\title{
Compact Facility for Testing Steady and Transient Thermal Performance of Building Walls
}

\author{
Aimee Byrne \\ Technological University Dublin, aimee.byrne@tudublin.ie \\ Gerard Byrne \\ Trinity College Dublin \\ Anthony Robinson \\ Trinity College Dublin
}

Follow this and additional works at: https://arrow.tudublin.ie/engschcivart

Part of the Civil Engineering Commons, Construction Engineering Commons, Construction Engineering and Management Commons, Dynamics and Dynamical Systems Commons, Engineering Mechanics Commons, Environmental Design Commons, Environmental Engineering Commons, Other Civil and Environmental Engineering Commons, Structural Engineering Commons, and the Structural Materials Commons

\section{Recommended Citation}

Byrne, A. Byrne, G. \& Robinson, A. (2017) Compact facility for testing steady and transient thermal performance of building walls, Energy and Buildings, Vol. 152, 2017, 602-614pp. ISSN 0378-7788, http://dx.doi.org/10.1016/j.enbuild.2017.07.086.

This Article is brought to you for free and open access by the School of Civil and Structural Engineering at ARROW@TU Dublin. It has been accepted for inclusion in Articles by an authorized administrator of ARROW@TU Dublin. For more information, please contact arrow.admin@tudublin.ie, aisling.coyne@tudublin.ie, gerard.connolly@tudublin.ie.

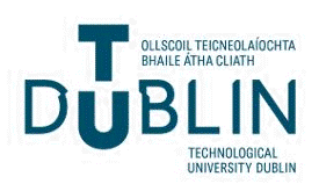




\title{
Compact facility for testing steady and transient thermal performance of building walls
}

\author{
Aimee Byrne $^{\mathrm{a}, *}$, Gerry Byrne ${ }^{\mathrm{b}}$, Anthony Robinson ${ }^{\mathrm{b}}$ \\ a School of Civil \& Structural Engineering, Dublin Institute of Technology, Ireland \\ b Department of Mechanical and Manufacturing Engineering, Trinity College Dublin, Ireland
}

\section{A R T I C L E I N F O}

\section{Article history:}

Received 30 March 2017

Received in revised form 25 July 2017

Accepted 28 July 2017

Available online 31 July 2017

\section{Keywords:}

Thermal resistance

Building energy

Heat transfer

Building envelope

Walls

Transient

Steady

\begin{abstract}
A B S T R A C T
Energy efficiency retrofit of buildings represents a key effort in reducing EU energy demand by $20 \%$ by 2020. However, predictions tend to overestimate savings by large percentages. The shortfall in savings can be attributed to incorrect predictive techniques, comfort takeback along with other behavioural and workmanship variables. Common predictive techniques related to heat loss tend to be based on the Uvalue of the building envelope. This paper presents the design of a more straightforward and compact version of the traditional Hot-Box apparatus (measures U-value) which instead determines the thermal resistance of samples of building envelope. U-value includes the need to measure/predict the effective surface resistances. In situ surface resistances, which include radiation and convection, are difficult to predict and vary depending on climatic conditions, exposure levels, surface emissivities among many other influences. The design of the test facility eliminates the need to incorporate these surface behaviour variables. This paper details the replicable apparatus and test methodology. The results of testing a hollow block wall of typical construction using the rig is then presented. The determined R-value is found to be within $1 \%$ of calculated values and the thermal time constant also matches closely with the most accurate predictive estimates.
\end{abstract}

(c) 2017 Elsevier B.V. All rights reserved.

\section{Introduction}

Buildings are responsible for $40 \%$ of the final energy consumptions and 33\% of the carbon emissions in Europe [1]. The estimated potential for energy savings within this sector is $90 \%$ by 2050 [2]. Directive 2010/31/EU on the energy performance of buildings (EPBD) is the main legislative instrument at EU level for improving the energy efficiency in buildings [3]. Recent efforts have focused on nearly zero energy buildings or 'nZEBs' [4]. Although most stringent requirements are intended for new buildings, Article 9(2) of the EPBD requires Member States to, "take measures such as the setting of targets in order to stimulate the transformation of buildings that are refurbished into nZEBs" [3]. Member States such as Ireland and Denmark have enacted specific measures for refurbishing existing buildings to nZEB levels as well as established particular building regulations for refurbishment. Most recently, the cost-optimal approach, which considers both financial and societal aspects, has become the focus [5]. The lack of data available on changes in

\footnotetext{
* Corresponding author.

E-mail addresses: aimee.byrne@dit.ie (A. Byrne), gerbyrne@tcd.ie (G. Byrne), arobins@tcd.ie (A. Robinson).
}

running costs due to major renovation of building elements has resulted in difficulties in calculating for cost-optimality [5].

Accurate prediction of thermal properties and behaviour of building elements under typical in-use conditions is essential for creating innovative products, optimizing current designs and producing more accurate data for cost-benefit analyses such as those required for cost-optimal design. Currently predictions are largely based on standardised U-values (thermal transmittance) of a given material or combination of material layers as input for calculation procedures such as the Dwelling Energy Assessment Procedure (DEAP) in Ireland [6] or the Standard Assessment Procedure (SAP) in the UK [7]. In order to better understand how buildings might behave under different circumstances, the thermal properties of building components need to also be quantified using experimental data. In addition, experimental data can provide insight into behaviours of building elements under specific local and dynamic boundary conditions that may be encountered in situ.

\subsection{Thermal transmittance of the wall system (steady state)}

One-dimensional, steady-state thermal network models can be used to represent many engineering systems including the plane or composite wall [8]. In a typical house during the heating season, 


\begin{tabular}{|ll|}
\hline \multicolumn{2}{|l|}{ Nomenclature } \\
$A$ & Surface area $\left(\mathrm{m}^{2}\right)$ \\
$C$ & Specific heat capacity $(\mathrm{J} / \mathrm{kgK})$ \\
$R$ & Thermal resistance $\left(\mathrm{m}^{2} \mathrm{~K} / \mathrm{W}\right)$ \\
$T$ & Temperature $(\mathrm{K})$ \\
$h$ & Heat transfer coefficient $\left(\mathrm{W} /\left(\mathrm{m}^{2} \mathrm{~K}\right)\right.$ \\
$L$ & Length $(\mathrm{m})$ \\
$\dot{m}$ & Mass flow rate $(\mathrm{L} / \mathrm{min})$ \\
$q$ & Heat flux $\left(\mathrm{W} / \mathrm{m}^{2}\right)$ \\
$v$ & Wind speed $(\mathrm{m} / \mathrm{s})$ \\
$w$ & Uncertainty $(\%)$ \\
$N u$ & Nusselt number \\
$k$ & Thermal conductivity of air $\left(\mathrm{W} /\left(\mathrm{mK}^{2}\right)\right)$ \\
$\varepsilon$ & Surface emissivity \\
$\sigma$ & Stefan-Boltzmann constant $\left(\mathrm{W} /\left(\mathrm{m}^{2} \mathrm{~K}^{4}\right)\right)$ \\
$\tau$ & Thermal time constant $($ hours $)$ \\
Subscripts \\
$a$ & Air \\
$c$ & Convective \\
$e$ & External (or cold side) \\
$i$ & Internal (or hot side) \\
in & Inflow \\
$m$ & The m-th layer \\
$m e a n$ & Mean \\
$n$ & Number of layers \\
out & Outflow \\
$p$ & Heat flow path \\
$r$ & Radiative \\
$s$ & Surface \\
surr & Surrounding surfaces \\
total & Total \\
$\mathrm{W}$ & Water \\
wall & Wall \\
$1,2,3$. & Layer number $1,2,3 \ldots$ \\
& \\
\hline
\end{tabular}

heat transfers to the internal wall surface by convection and radiation from the warm internal environment. Heat transfers mainly by conduction through the wall layers, and disperses from the external surface by convection and radiation from the face of the wall to the colder external environment. In the case of Fig. 1, the hot side is the internal heated space and the cold side is the external colder ambient air. In this example the composite wall is made up of three materials of different thermal resistances, resulting in a different temperature gradient across each layer.

For a unit area, U-value is equal to the inverse of the total thermal resistance of the system,

$U A=\frac{1}{R_{\text {total }}}$

The total thermal resistance being;

$R_{\text {total }}=R_{\text {etotal }}+R_{\text {wall }}+R_{\text {itotal }}$

The surface resistances includes both radiative and convective resistances, given as,

$$
\begin{aligned}
& R_{\text {etotal }}=\frac{1}{R_{r e}+R_{c e}} \\
& R_{\text {itotal }}=\frac{1}{R_{r i}+R_{c i}}
\end{aligned}
$$

BS EN ISO 6946:2007 [9] suggests the use of $0.13 \mathrm{~m}^{2} \mathrm{~K} / \mathrm{W}$ for $R_{\text {itotal }}$ and $0.04 \mathrm{~m}^{2} \mathrm{~K} / \mathrm{W}$ for $R_{\text {etotal }}$ for typical walls. However, the values can also be calculated using the convective coefficient, $h_{c}$, and the radiative coefficient, $h_{r}$.

\subsubsection{External convective coefficient}

The surface resistance due to convection can be calculated as follows:

$R_{C}=\frac{1}{h_{c} A}$

In this equation the convective coefficient, $h_{c}$, can be measured at the location using Eq. (6);

$h_{c}=\frac{q_{c}}{T_{s}-T_{a}}$

where $q_{c}$ is the convective heat flux, $T_{s}$ is the surface temperature and $T_{a}$ is the air temperature [8]. $q_{c}$ can also be estimated through calculation for case specific circumstances.

For external surfaces, according to BS EN ISO 6946:2007 [9], $h_{c}$ can be approximated as $4+4 v$, where $v$ is the wind speed adjacent to the surface $(\mathrm{m} / \mathrm{s})$. Many empirical models exist that correlate $h_{c}$ and $v$ in specific cases though there is a high uncertainty in the values predicted by such simplified empirical correlations [10].

Existing studies report widely different values for the influence of $h_{c}$ on the building energy consumption. Choice of the convection model used can result in a variability in energy consumption of up to $30 \%$ for external surfaces [11]. External $h_{c}$ also depends on several other factors other than heat flow direction and wind speed; for example roughness of the surface and air flow pattern. The McAdams model is the most commonly used in heat transfer programs [11]. It includes three factors related to surface resistance alongside wind speed for determining $h_{c}$ for the external surface [12]. This results in rough surfaces implying a $h_{c}$ value of up to $10 \%$ higher than for smooth surfaces. The use of other common models can result in a difference in $h_{c}$ of up to $117 \%$ due to changing the input for roughness [11].

The arrangement and geometry of neighbouring buildings as well as the surrounding terrain can change drastically over the lifetime of a building. Local air flow patterns around a building strongly depend on these surroundings [12-14]. Since convective heat transfer varies with time depending on local air flow patterns, an adaptive $h_{c}$ algorithm has been suggested as the most accurate method to use in building simulations [15].

\subsubsection{Internal convective coefficient}

For internal surfaces, $h_{c}$ is dependant on the direction of heat flow. For standard upright walls the value used is typically assumed to be $2.5 \mathrm{~W} /\left(\mathrm{m}^{2} \mathrm{~K}\right)$ [9] or it can be measured using Eq. (6). In the absence of knowing the variables of temperature difference and heat flow, $h_{c}$ can be estimated using Nusselt number;

$h_{c}=\frac{N u \cdot k}{L}$

Here $\mathrm{k}$ is the thermal conductivity of the air, and $\mathrm{L}$ is the length of the room. $\mathrm{Nu}$ is a function of Ra (modified Rayleigh number based on height) and $\operatorname{Pr}$ (Prandtl number), for natural convection and a function of Re (enclosure Reynolds number), Pr and L/D for forced convection. Therefore, $h_{c}$ is a function of surface geometry, air properties, and temperature difference between the surface and ambient air.

Different constants, equations and models have been used for internal $h_{c}$ as presented in the Appendix of Obyn $\&$ van Moeseke [16] publication. Commonly used $h_{c}$ constants and common $h_{c}$ correlations as a function of temperature difference between surfaces and air have been shown to result in significant deviations in the coefficient (up to $80.9 \%$ ). This results in an impact on predicted annual heating demand of up to $18.3 \%$ and annual cooling demand of up to $10.9 \%$ [16]. 

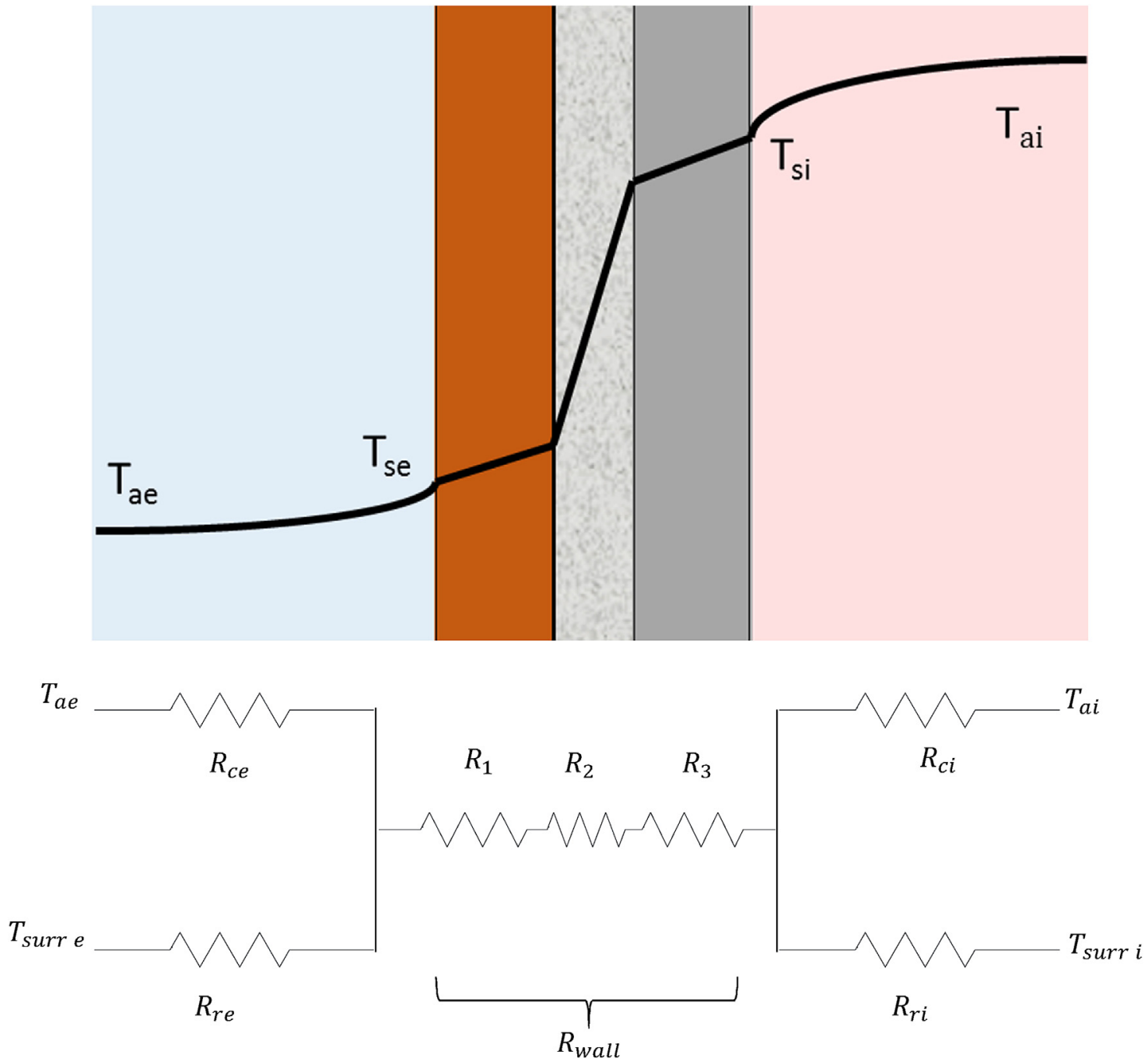

Fig. 1. Heat transfer through the composite wall by conduction, convection and radiation.

\subsubsection{Radiative coefficient}

The surface resistance due to radiation $R_{r}$ used in Eqs. (3) and (4), is dependent on the radiative coefficient $h_{r}$.

$R_{r}=\frac{1}{h_{r} A}$

Where, according to BS EN ISO 6946 (2007);

$h_{r}=\varepsilon h_{r o}$

$\varepsilon$ is the emissivity of the surface usually assumed to be 0.9 , however, Marino et al. [17] found that the application of low emissivity coatings can increase the internal surface resistance by $26.5 \%$ thereby, reducing winter thermal needs up to $12.5 \%$. Similarly for summer cooling, Han et al. [18] found that for roof surfaces, the cooling load reduction ratio for white painted surface could be as much as $9.3 \%$.

$h_{r}$ is highly dependent on temperature. In Eq. (9), $h_{r o}$ is the radiative coefficient for a black-body surface which varies between 4.1 and $6.3 \mathrm{~W} /\left(\mathrm{m}^{2} \mathrm{~K}\right)$ depending on the temperature or it can be approximated as,

$h_{r o}=4 \sigma T_{\text {mean }}$

$\sigma$ is the Stefan-Boltzmann constant $\left(5.67 \times 10^{-8} \mathrm{~W} /\left(\mathrm{m}^{2} \mathrm{~K}^{4}\right)\right)$ and $T_{\text {mean }}$ is the mean temperature of the surface and surroundings [9].
Typically solar radiation is considered as operating on the external building surface and on the internal surface due to the presence in the indoor environments of a shortwave radiant field.

$h_{\mathrm{r}}=\varepsilon \sigma\left(T_{s}^{2}+T_{\text {surr }}^{2}\right)\left(T_{s}+T_{\text {surr }}\right)$

Convective and radiative heat transfer coefficients are often combined to give an effective internal surface coefficient $h_{i}$ and external $h_{e}$ [19]. If $T_{\text {surr }}=T_{a}$ the radiation effect can be accounted for by replacing the surface heat transfer coefficient $h_{c}$ in the convection resistance relation Eq. (5).

$h_{i}$ or $_{e}=h_{\text {riorre }}+h_{\text {ciorce }}$

Leading to the total surface resistance Eq. (5) becoming,

$R_{i \text { total }}$ or $R_{\text {etotal }}=\frac{1}{h_{\text {i ore }} A}$

Often in practice, radiative heat transfer is assumed to be negligible, leading to the total surface resistance being determined by Eq. (5) alone. Reflecting this, in transient measurements, the radiative resistance $R_{r}$ has been found to have only a minor influence on the thermal time constant [10]. However, other research into transient behaviour of walls has shown that the presence of internal shortwave radiant loads gives rise to a reduction in the decrement factor in terms of energy in winter, and an increase in summer [20]. 


\subsection{Thermal resistance of the wall}

In multi-layered samples of non-homogenous materials the heat transfer through the wall alone (i.e. heat transfer from the surface on one side to the surface on the other) can be simplified as follows:

$Q_{\text {wall }}=\frac{T_{s i}-T_{s e}}{R_{\text {wall }}}$

Therefore, by placing temperature sensors on the internal and external surfaces of the wall and knowing the heat transfer through the wall, under steady state conditions the thermal resistance of the wall alone, excluding surface resistances, can be determined. Thus, measuring thermal properties of the wall in this way eliminates some of the variables which can lead to inaccurate predictions of the behaviour of the wall in situ, in the sense that by focusing on the determination of $R_{\text {wall }}$ in the laboratory, the local conditions that govern $R_{\text {itotal }}$ and $R_{\text {etotal }}$ do not need to be known. In this way, measured or estimated convective and radiative heat transfer coefficients can then be determined on a case by case basis.

The measurement of heat transfer across materials can be performed using various standardised laboratory tests [21]. Measuring or estimating thermal properties of building materials can be key in obtaining the optimum performance for a particular application. A number of laboratory experimental apparatus have been designed for this purpose, though these tend to be designed for small, desktop samples, usually of only one material component [21-24]. The standardised guarded hot plate and heat flow meter method [25] also tends to be for small samples [21-26].

For the typical building envelope system, such as walls, which are usually composed of different material layers, heat transfer can be two- or three- dimensional. The standardised method for examining heat flow in a sample of building envelope in the laboratory is the Hot-Box method [27], of which there are a couple of variations; the guarded Hot-Box, the calibrated Hot-Box [28] and the metered hot box [29]. Measurements are normally taken under steady-state conditions but the calibrated Hot-Box can also make dynamic measurements. The commonality between the different variations of the Hot-Box apparatus/method is the requirement for two closed convective chambers of controlled temperatures, one being hot, the other cold and the test specimen divides the two enclosures. The total footprint of the apparatus tends to be very large because of the chambers and air conditioning and monitoring systems. The amount of heat transferred from one side of a specimen to another for a given temperature difference is determined but this value is not dependant on the modes of heat transfer (conduction, convection or radiation) [30]. The convection in the chambers depends on air temperature and velocity, the radiation depends on temperatures and total hemispherical emittance of the specimen surface and surfaces "seen" by the specimen. The steady-state testing, therefore, gives a measure of the total thermal resistance of the overall thermal network including the wall and surface resistances [31] by measuring the power necessary to maintain the hot chamber at a constant temperature. Dynamic testing involves changing the temperature on one side of the wall. The guarded Hot-Box also incorporates a guarded box around the metered box in which the environment is controlled, limiting lateral heat flow to the specimen as well as heat flow through the meter box walls [30] This format has been extensively used in research of the thermal characteristics of building walls [31-33]. Due to its typically large size, for example $2.4 \times 2.4 \times 2.4 \mathrm{~m}$ inner volume per chamber [34], one group of researchers designed a smaller version of the apparatus called the "Small Hot-Box" [35]. However, by reducing the overall size of the apparatus, the sample size is limited to $0.3 \times 0.3 \mathrm{~m}$ area. Similar designs have also been created that are smaller but still incorporate the use of chambers typical of the Hot-Box [36].
As discussed in Section 1.1, in situ surface heat transfer via radiation and convection can be unpredictable and vary depending on air flow, exposure levels, surface emissivities among many other environment dependant parameters. Although testing under controllable conditions in the laboratory using test facilities such as the Hot-Box offers the advantage of being replicable under closeto-identical conditions, in reality the wall in situ would be exposed to dynamic boundary conditions of the internal and external environments of which it is difficult to replicate in the hot and cold chambers. This has led to the formation of a number of correction values [37]. It was, therefore, decided to devise a way of examining the heat flow through the wall components and omitting the variables of radiation and convection at the internal and external surfaces and environments. Although heat transfer delivered by conduction only is more common for small or single material testing [21-25], these apparatus have not been built on a scale or to a design that could incorporate a building wall sample. Heat transfer through the wall alone can also be examined in situ or in the laboratory, using heat flux sensors and thermocouples placed on the wall surface $[38,39]$. However, this method can only determine the heat flow at a particular location, which may not give an accurate reflection of the wall's true behaviour, particularly for inhomogeneous wall types such as the cavity block wall. Furthermore, other methods would need to be employed to control the environment either side of the wall in order to replicate the tests presented here. This paper details the design of a replicable test rig which expands and adapts previous designs with the intention of limiting errors and facilitating the testing of walls using a more compact apparatus than the commonly used Hot-Box. The rig was designed and built in the Thermodynamics Laboratory in Trinity College Dublin. The apparatus allows the evaluation of the thermal resistance of homogeneous and non-homogeneous multi-layered composite systems as well as the behaviour of those systems under chosen constant or varying thermal loading conditions.

To determine the veracity of the apparatus, a sample of hollow block wall with typical plaster finish was tested for thermal resistance (steady-state) and thermal time constant (transient-state). Bricks and blocks with cavities inset are common to residential construction [40] and present particular difficulty in determining true effective thermal conductivity due to two or three dimensional conduction through the thermal bridging portion that makes up the solid frame and a combination of the heat transfer by natural convection and radiation through the inner air-cavities [41]. These wall types also create a difficulty when introducing insulation during energy efficiency retrofit. Hollow blocks possess a lower thermal mass than solid walls of the same thickness. It has, therefore, been shown that lighter internal layer thermal mass results in less benefit during insulation retrofit [38,39]. The following sections detail the specifications for the rig before examining the results of testing on the wall as compared to calculated and published values for this wall type. The verification of the method facilitates future testing with the rig on building envelope samples with and without retrofitted insulation.

\section{Rig design specification}

There were a number of aims in detailing and building the test rig. The first was to present a viable, more compact alternative to the Hot-Box method for building walls or other flat surface building elements which could be replicated in other building envelope research laboratories. The second was to present a rig that would not include the requirement for convective and radiative surface heat transfer at the faces of the wall, thus eliminating many of the uncertainties associated with these parameters. Similar to the HotBox, the rig comprises a heat source on one side of the test specimen 


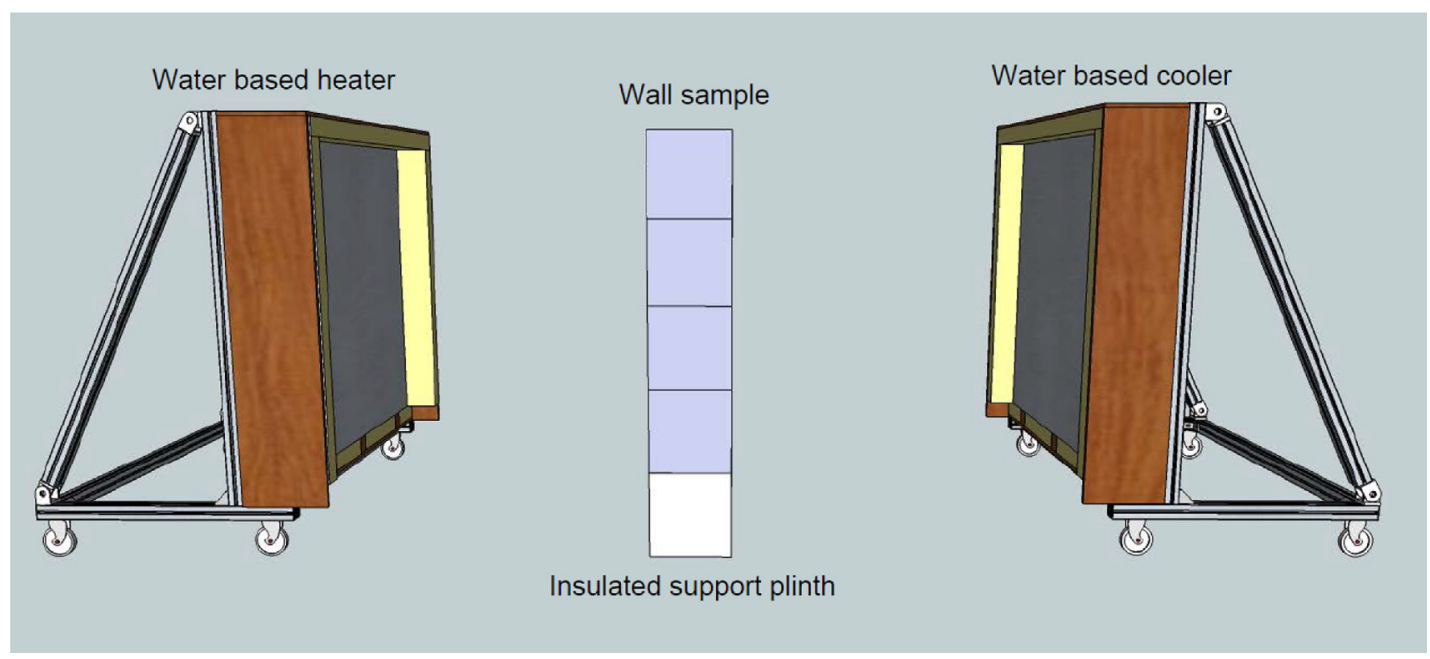

Fig. 2. Overall layout of the test facility.

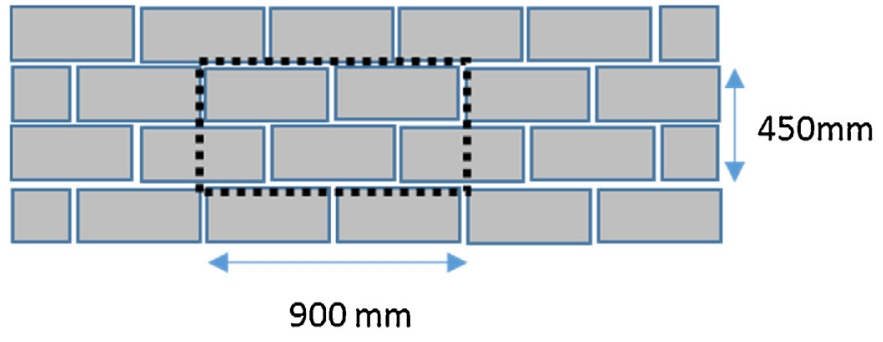

Fig. 3. Typical Block wall layout with $10 \mathrm{~mm}$ mortar joint.

and a heat sink on the other, as depicted in Fig. 2. However, unlike the Hot-Box, the heat delivery is via conduction using hot and cold plates and thermal contact mats.

The dimensions of the test rig are governed by the sample size requirement. Requirements for the Hot-Box method suggest that the metered area should be large enough to be representative of the full system [30] and it is typical to use a single module example of the full structure or a multiple of this. Typical hollow blocks in Ireland are $215 \mathrm{~mm}$ high, $440 \mathrm{~mm}$ wide and $215 \mathrm{~mm}$ thick and arranged in a staggered manner as shown in Fig. 3. A single repeating module of block and mortar is as shown Fig. 3 as $900 \mathrm{~mm}$ wide and $450 \mathrm{~mm}$ high to include the repeating units of block and $10 \mathrm{~mm}$ mortar joints which are installed as staggered sets. It was decided that a multiple of two of these modules would present a symmetric sample making the overall sample size $900 \times 900 \mathrm{~mm}$ surface area. This sample space facilitates a large range of common building block types [42].

\subsection{Hot and cold plates}

As shown in Fig. 4, main aluminium plates provide the heat source and sink to the wall surface. Directly behind the plate is a layer of rigid thermal insulation panelling. The insulation chosen for the rig design needs to be of a considerably lower thermal conductivity than that of the wall sample in order to reduce heat flow through the rig to the ambient surroundings. Kooltherm K5, $70 \mathrm{~mm}$ thickness, was chosen which has a thermal conductivity of down to $0.02 \mathrm{~W} /(\mathrm{mK})$. This ensured that the path of least thermal resistance would be through the wall sample even after typical external insulation is retrofitted to the specimen. The typical insulation used for retrofitting at the time of this study was EPS 100, which has a thermal conductivity of $0.035 \mathrm{~W} /(\mathrm{mK})$.
Behind the insulation layer is the guard plate as shown in Fig. 4. The guard plate minimises the influence of temperature changes in the laboratory and helps to ensure a controlled temperature behind the heater or cooler plate. Because the guard plate is controlled to the same temperature as the main plate, there is minimal temperature difference between them. This strategy vastly reduces any energy flow away from the specimen through the back of the main plates, eliminating thermal gains or losses from the main cold and hot plates respectively in this direction. A further layer of insulation is behind the guard plate and to the sides, top and bottom of the rig. The plates had to be mounted on three wooden blocks as shown in the diagram to prevent the insulation from being crushed by the weight of the plates. The whole system fits within a $19 \mathrm{~mm}$ plywood frame. The frame and insulation extend $50 \mathrm{~mm}$ out from the plate face to fit around the wall sample. The frame in turn is attached to an aluminium support structure on wheels.

Other heat source and heat sink options, such as mats, could be used to replace those designed here, depending on the boundary condition requirements for the project. A water based system for heating and cooling was designed so as to allow for a wide range of boundary temperatures to be used. The water channel is embedded within the metal plates to limit heat losses and ensure even contact with the plate (Fig. 5). The plates had to be assembled from smaller sections to facilitate machining of the channels. These sections were then fastened together using male and female slots and sealed with silicon sealant.

A PVC back plate was bolted to the aluminium plate using machined groves in the PVC plates and machined threaded holes in the aluminium plates. Furthermore, the connection was sealed using silicon sealant. This is shown in Fig. 6. This figure also displays the fittings inserted and glued into the plate. These were to facilitate plastic piping to allow the transfer of fluid from one channelled section to the next. Piping was fed through drilled holes in the frame and insulation.

A Fischerbrand IsoUK 250LC closed system circulator unit was used to control the temperature and flow of water. Flow from the unit was split in two, one to the main plate and the other to the guard plate. The out flow from the respective plates was rejoined before returning to the circulation unit. This ensured that the water temperature provided to each plate was the same, while allowing for the temperatures and flow rates of the main plate to be accurately, and separately, measured. The temperature probes were attached at the inlet and outlet ports of the heater and cooler plates. The flow was measured using the two low flow meters (0.07-0.55 L/min) shown in Fig. 5 and controlled using valves. 


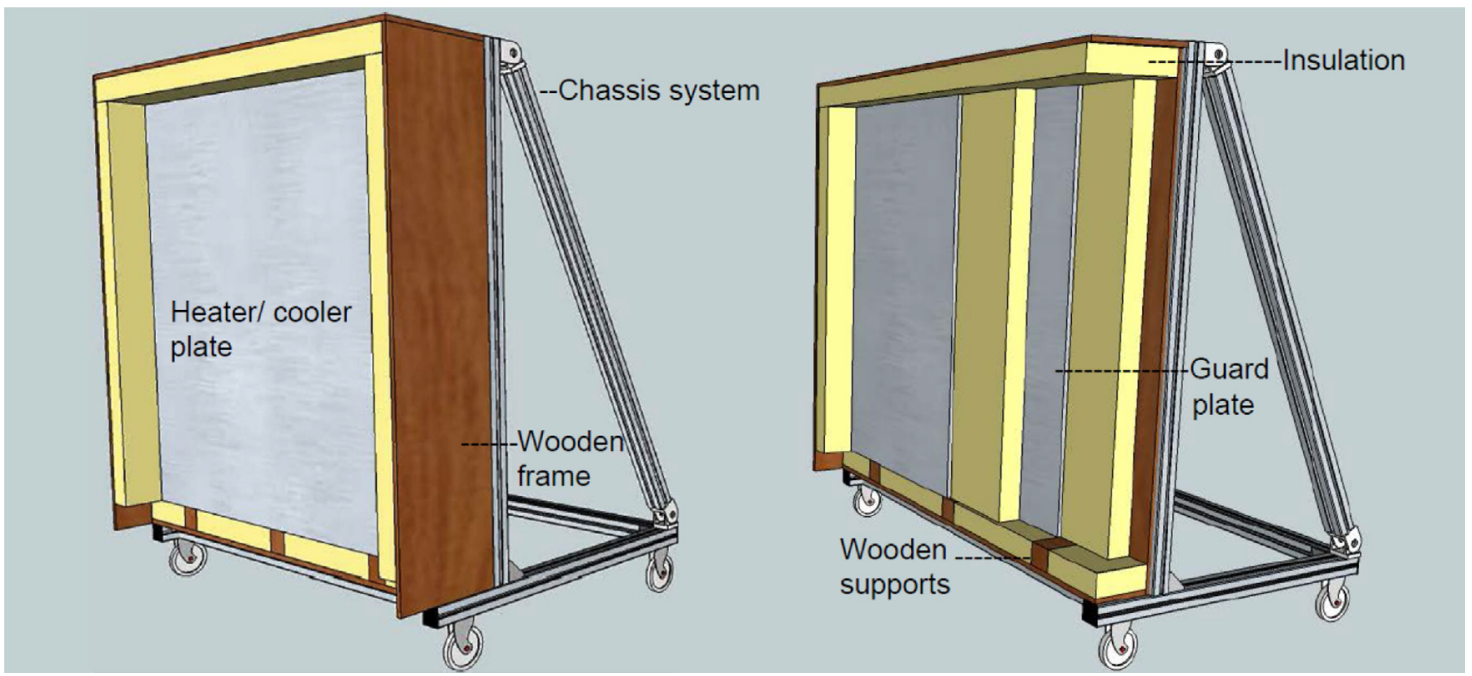

Fig. 4. Heater and cooler plates.

\section{K-type thermocouple probe}

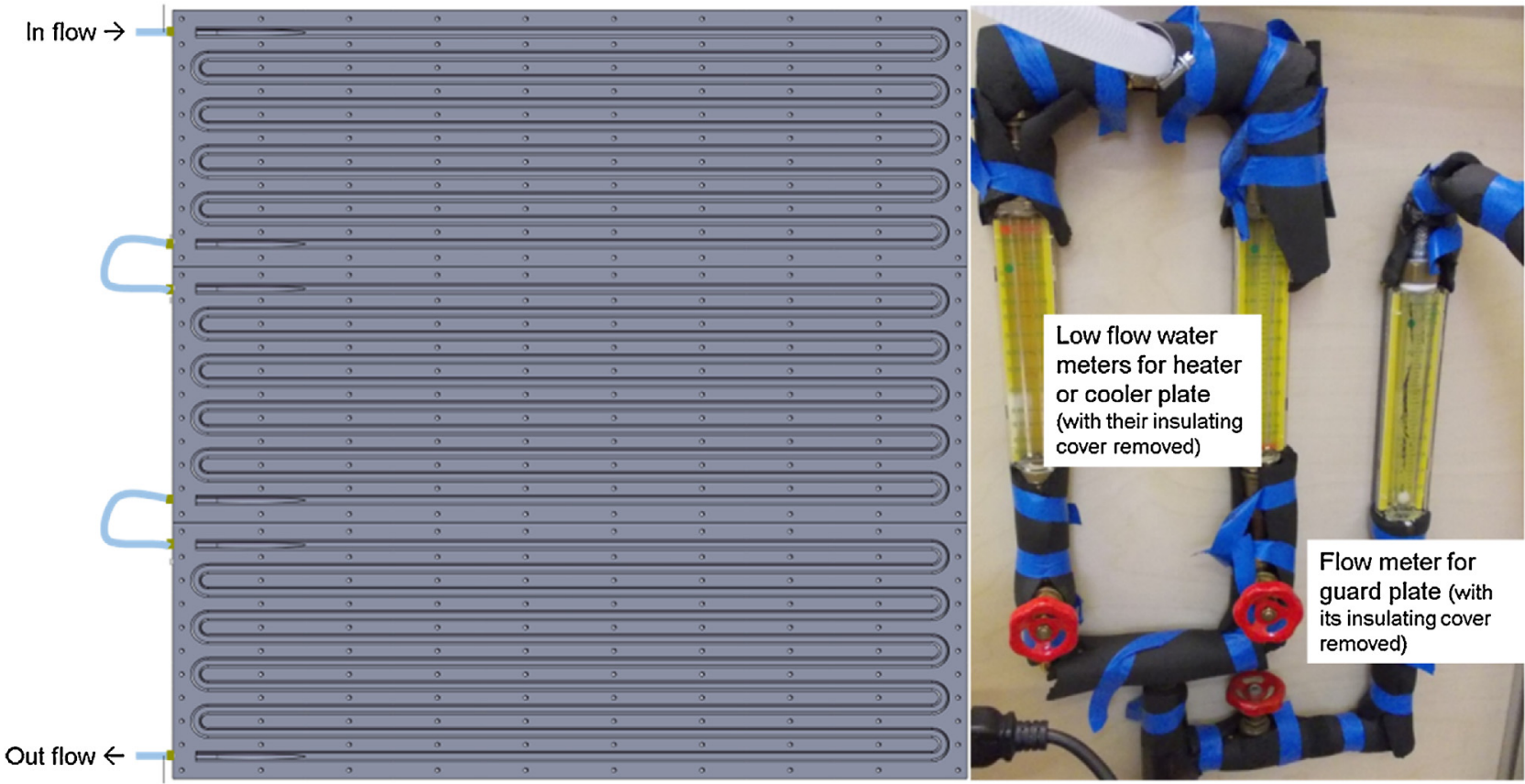

K-type thermocouple probe

Fig. 5. Internal channels of plates showing the location of temperature measurement on in and out flow, and flow meters to measure flow to the heater/cooler plate and guard plate.

\subsection{Design principals}

The rig was designed based on the first law of thermodynamics. The first law states that the addition of a quantity of heat to a control volume in time will increase its energy and also perform work [43];

$\frac{d Q}{d t}=\frac{d E}{d t}+\frac{d W}{d t}$

This law observes the principle of conservation of energy. Under steady-state conditions heat flows at a constant rate through any cross section parallel to the surfaces of the plate. Ideally, therefore, in the absence of any substantial heat loss, when steady state is achieved the heat provided by the hot side of the rig should equal the heat flow through the wall sample and the heat removed at the other side of the sample on the cold side. This means that for Fig. 7 , all $q_{x}$ should, in principle, become equal. A steady-state of heat flow occurs when $q_{x}$, calculated from Eq. (16), is equal for both the hot and cold plate systems. A value for thermal resistance, $R$, is then calculated using this value for $q_{x}$ and recorded surface temperature values either side of the wall sample using Eq. (17).

$q_{x}=\dot{m} \mathrm{c}\left(T_{w, \text { out }}-T_{w, \text { in }}\right)$

$q_{x}=\frac{T_{s e}-T_{s i}}{R}$

Water temperatures at the inlet and outlet of the main plates provided values for $T_{w, \text { out }}$ and $T_{w \text {,in }}$ in Eq. (16) and water flow is determined using the water meters displayed in Fig. 5. Nine thermocouples provide the average surface temperature of the wall sample at various locations on either side ( $T_{s e}$ and $T_{s i}$ in Eq. (17)). 

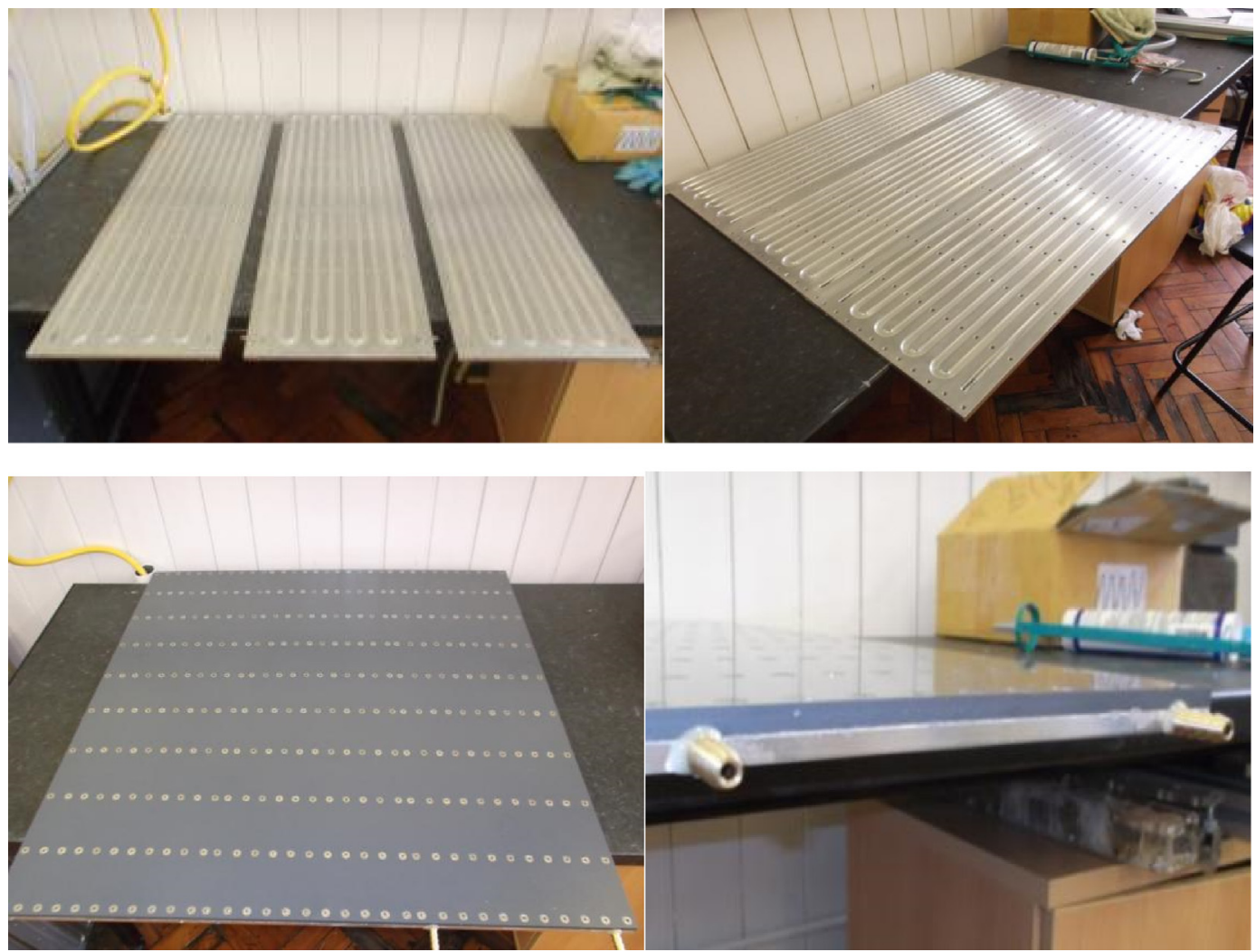

Fig. 6. Assembly of plates.

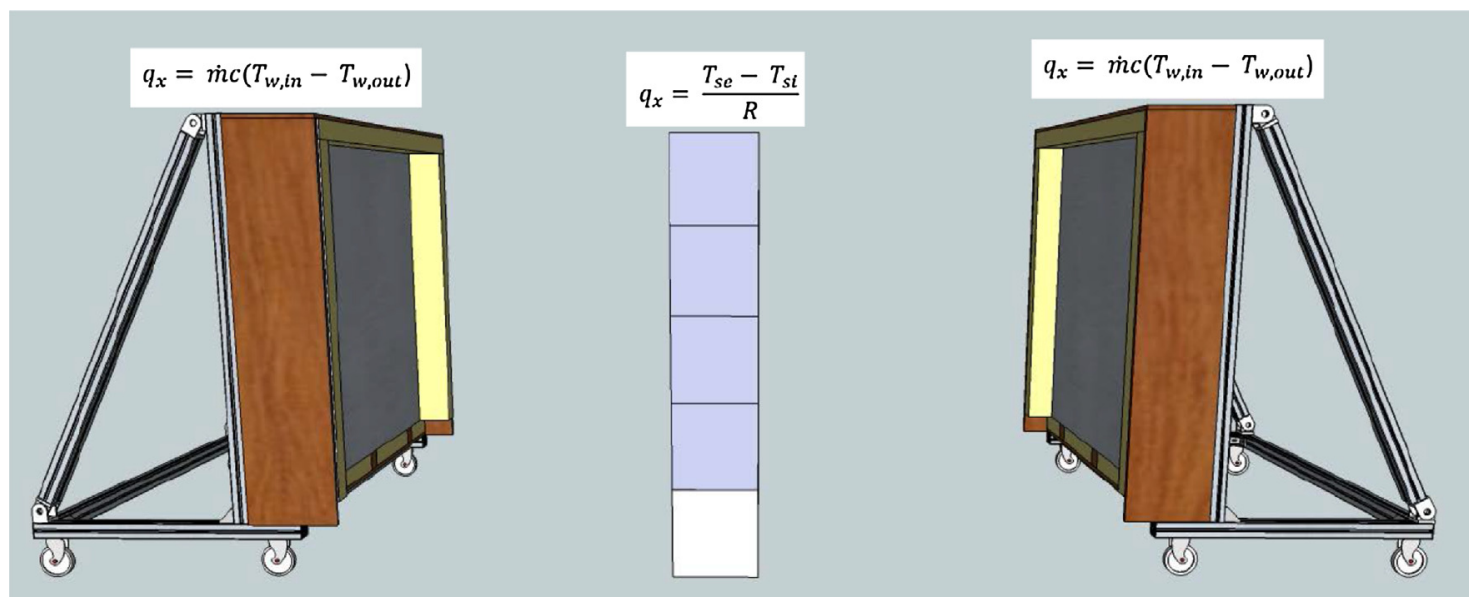

Fig. 7. Graphical representation of energy balance in the test rig.

These are placed at locations which represent all of the different possible heat flow route types through wall sample. For the hollow block wall sample, this includes through the web, the cavity and the mortar joints at various levels and intersections as per Fig. 8. This placement design also allows for readings close to all stages of the water delivery loop from inlet to outlet. A summary of the data recording methods for parameters in Eqs. (16) and (17) are listed in Table 1. Additional measurements were taken to determine losses and therefore eliminate errors. These are listed in Table 2 including an explanation for the measurements.

All thermocouples were attached to a Data Acquisition System (DAQ) and recorded to spreadsheet files using LabVIEW. The flow rate measurements were taken manually and recorded. Further to the losses determined using the thermocouples listed in Table 2,
Table 1

List of measurements required for tests on the rig.

\begin{tabular}{|c|c|c|}
\hline Value needed & Description & Sensor \\
\hline$T_{s i}$ & $\begin{array}{l}\text { Wall surface temperature hot } \\
\text { side }\end{array}$ & 9 type-T thermocouples \\
\hline$T_{s e}$ & $\begin{array}{l}\text { Wall surface temperature cold } \\
\text { side }\end{array}$ & 9 type- $\mathrm{T}$ thermocouples \\
\hline$T_{w, \text { in }}$ & $\begin{array}{l}\text { In-flow on the hot and cold } \\
\text { side plates }\end{array}$ & 2 type-K thermocouple probes \\
\hline$T_{w, \text { out }}$ & $\begin{array}{l}\text { Out-flow on the hot and cold } \\
\text { side plates }\end{array}$ & 2 type-K thermocouple probes \\
\hline$\dot{\mathrm{m}}$ & $\begin{array}{l}\text { Flow of water through hot and } \\
\text { cold side plates }\end{array}$ & $\begin{array}{l}4 \text { low-flow flow meters } \\
(0.07-0.55 \mathrm{~L} / \mathrm{min})\end{array}$ \\
\hline
\end{tabular}



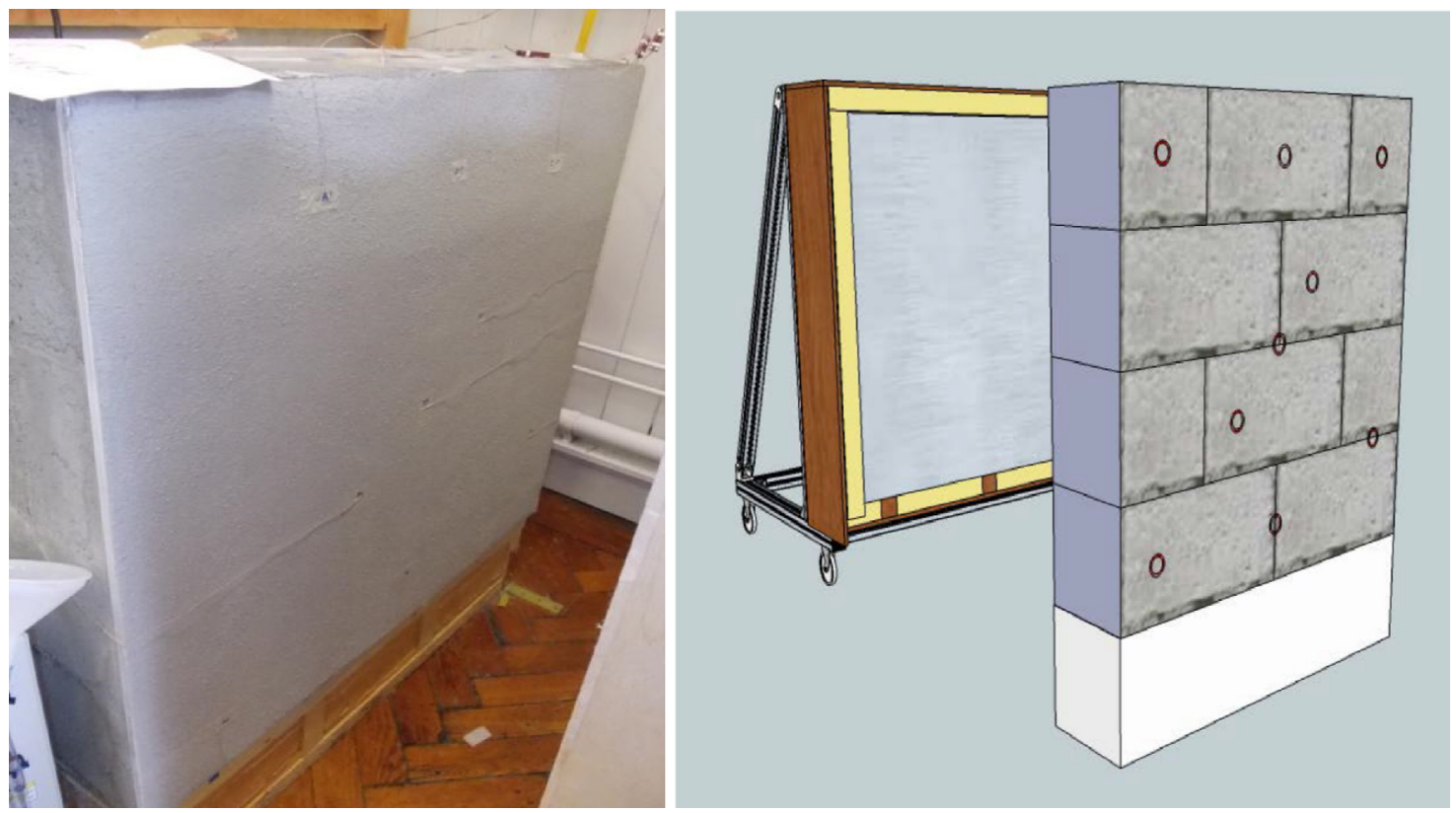

Fig. 8. Locations of thermocouples on wall surface.

Table 2

List of additional measurements recorded to increase the accuracy of the rig measurements.

\begin{tabular}{ll}
\hline Description & Sensor \\
\hline $\begin{array}{l}\text { Flow to the } 2 \text { guard plates. Measured to ensure } \\
\text { that the guard plates are maintaining a flow }\end{array}$ & 2 flow meters $(0.2-2 \mathrm{~L} / \mathrm{min})$ \\
from the circulation unit & \\
Heat loss through the surrounding Kooltherm & 4 type-T thermocouples \\
insulation of the rig. Two temperature \\
sensors are placed on the top of the wall and \\
another is placed in the centre of the \\
insulation above the main plates on both \\
sides of the rig. \\
$\begin{array}{l}\text { Ambient temperature. This is measured on } \\
\text { both sides of the rig. }\end{array}$ \\
$\begin{array}{l}\text { Surface temperature on the main plates at two } \\
\text { locations to ensure uniformity of heat supply } \\
\text { or removal. }\end{array}$ \\
\hline
\end{tabular}

Table 3

Experimental Uncertainties.

\begin{tabular}{ll}
\hline Measurement & Error and uncertainty \\
\hline Temperature (calibrated) (Type-T or Type $-\mathrm{K}$, & $\pm 0.1^{\circ} \mathrm{C}$ \\
Omega thermocouple) & $\pm 0.011 \mathrm{~L} / \mathrm{min}$ \\
Mass flow rate & $6.98-8.31 \%$ \\
Heat Flux (Eq. (16)) & $7-8.39 \%$ \\
Thermal resistance (Eq. (18)) & \\
\hline
\end{tabular}

spot assessments of heat loss through the rig walls were made using a Resistance Temperature Detector (RTD) probe accurate to within $\pm 0.1^{\circ} \mathrm{C}$.

\subsection{Heat loss measurement and limitation}

Table 3 lists the measurement uncertainty associated with the various measurement devices required for building this rig. For accurate determination heat flow across the wall sample, precise temperature measurements, particularly in the water inlet and outlet, are required. To avoid unwanted interference between high voltage systems and the thermocouple measurement system, as well as additional cold junction compensation errors, a specialized ice bath was constructed to the specifications outlined in ASTM
STP470 [44]. The bath is known to be isothermal and maintain a constant temperature of $0.01^{\circ} \mathrm{C}$, as the standard specifies. The total emf was then converted to a temperature measurement using individual system calibration curves for each thermocouple. The calibrated accuracy was within $\pm 0.1^{\circ} \mathrm{C}$. The accuracy of the flow measurement units were $\pm 2 \%$ of the full scale deflection on the rotameter-type flow meter. Therefore, this value was $\pm 0.011 \mathrm{~L} / \mathrm{min}$ or an error of up to $\pm 2.6 \%$.

The total uncertainty in measured thermal resistance of the wall sample is the propagation of uncertainties of the constituent parts in the following Eq. (18);

$R_{\text {wall }}=\frac{T_{\mathrm{se}-} T_{\mathrm{si}}}{\dot{m} \mathrm{c}\left(T_{\mathrm{w},} \text { out }-T_{w, \quad \text { in }}\right)}$

For the purpose of uncertainty calculation, each measurement is denoted by $x_{i}$ and the uncertainty in the measurement $w_{i}$. The result of a calculation using these measurements is denoted $\mathrm{Z}$ and the uncertainty in the calculated result is denoted by $w_{z}$. The uncertainty $w_{z}$ is calculated using the method of Kline and McClintock [45] using the following equation:

$w_{z}=\sqrt{\sum_{i=1}^{n}\left[\frac{\partial Z}{\partial x_{i}} w_{i}\right]^{2}}$

The maximum experimental uncertainties are summarized in Table 3.

Heat lost through the rig walls was calculated using Eq. (17) and input of internal and external surface temperature and the manufacturer provided thermal resistance value for that Kooltherm material. The area over which heat could be lost through the rig was measured. The temperature values in the equation were taken from those in Table 2 and spot readings using an RTD probe. It was assumed that due to the presence of a guard heater and cooler that losses through the two back faces of the rig were negligible. Once steady state was achieved, the thermocouples measuring losses could be moved to many more locations around the rig as well as embedded within the surrounding insulation. The losses were characterised for the various locations by examining this data and it was found that the loss variation was relatively low. Total heat losses through the rig structure to the ambient laboratory were estimated 


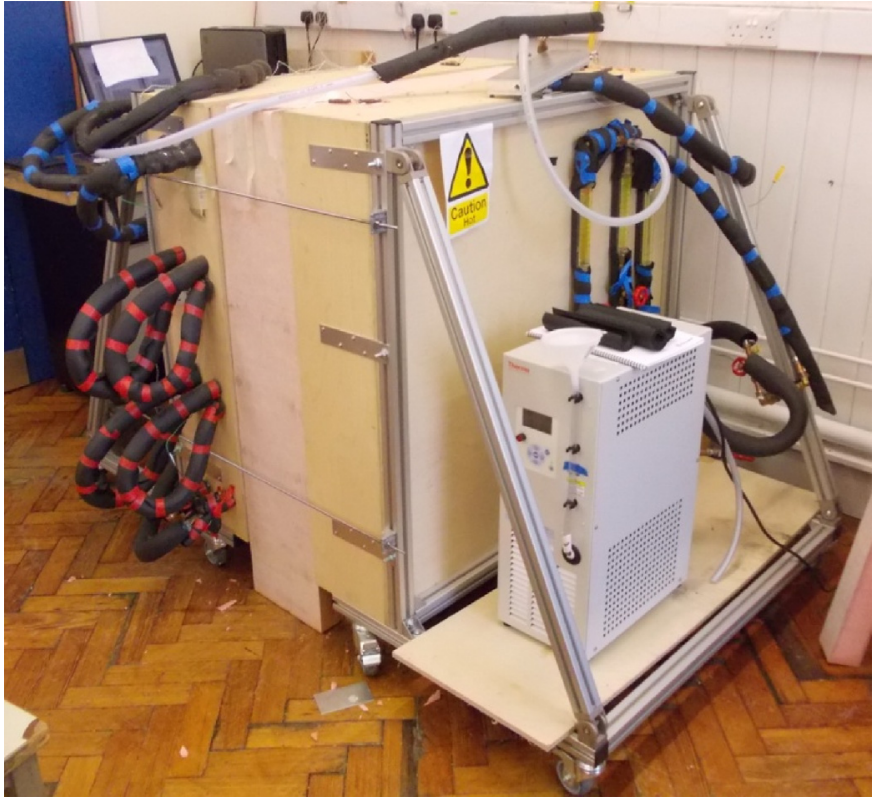

Fig. 9. Rig during testing.

to be approximately $1.1 \mathrm{~W}$ during testing, which is under $2 \%$ of the energy input. This value was removed from the total energy supply calculations before determining the thermal resistance of the wall sample.

\section{Methodology}

\subsection{Wall sample preparation}

The wall sample is built and adequate time allowed for the materials to dry out. The measurement sensors are attached at positions as per Fig. 8. An estimation of likely heat flow for a set steadystate temperature gradient across the wall is determined using an estimation for the thermal resistance by standard calculation procedure $[9,46-48]$ along with some actual building properties listed in supplier information [49].

Once the silicon thermal pads are attached to the face of the heater and cooler plates, the two sides of the rig are pushed together, enclosing the wall sample. The remaining gaps are filled with more Kooltherm K5 insulation board to ensure a sealed system. The two sides of the rig are then clamped and tightened into place using threaded bars (Fig. 9).

\subsection{Steady-state testing}

Temperatures were set to record every 60s. Flow readings were taken manually. The circulation units were set at specified temperatures to ensure an adequate temperature gradient across the wall sample $\left(20^{\circ} \mathrm{C}\right)$, and the required water flow was estimated using assumed thermal resistance values and equating Eqs. (16) and (17). Adjustments to the flow were made along with changes to the water supply temperatures and left to stabilise (with small adjustments $2 \mathrm{~h}$ was found to be sufficient). This was repeated until the energy supply on both sides of the wall were equal $\left(\operatorname{hot}_{x}=\operatorname{cold} q_{x}\right)$.

The wall surface temperatures were averaged for either side of the wall, removing the maximum and minimum readings. A value for energy loss was calculated as per Section 2.3 using the readings across the rig insulation from Table 2. Equating $q_{x}$ values as per Fig. 7, the $R_{\text {wall }}$ value is determined using Eq. (18). The test was repeated for another two boundary temperature settings to ensure consistency of the thermal resistance of the wall.

\subsection{Transient testing}

Although steady state tests give insight into the expected thermal behaviour of the building envelope and are simple to implement in predictive calculations, they may not in all cases be physically representative of the actual thermal phenomena. Many heat transfer scenarios are time dependant, or transient. Transient effects must be considered when boundary conditions change at a rate which is faster than that which the building envelope can respond. The thermal time constant, $\tau$, of a building envelope is the main property of that element that influences the damping effect it has on the internal space's temperature swings (relative to outdoor swings). It is the time required to come to within $1 / \mathrm{e}(36.8 \%)$ of the fixed value after a step thermal disturbance of the system. In a system that is heating, the time constant is the time for the system's step response to reach $1-1 / \mathrm{e}=63.2 \%$ of its final (asymptotic) steady-state value. In its basic form, it is the sum of the products of heat capacity and resistance $\sum R C$. For building walls it is the transient output response (a delay) of the multi-layered wall under the influence of a step change in temperature on one side

In order to allow for the introduction of a step change in temperature at one side of the wall sample, the plumbing for the system was reorganised so that the cold circulator unit fed both the heater and cooler plates, thus cooling both plates and the enclosed wall sample. The hot circulation unit piping was rearranged so that the hot water from it did not circulate through any plate, but simply flowed through an extension of piping and was recirculated back to the unit. Valves were installed into the plumbing system to control the flow on each pipe flowing and returning from the plates. They were positioned so that they could be used to switch the water source from the cold circulator unit to the hot circulator unit instantaneously. Temperature readings were set to record every $30 \mathrm{~s}$. The test begins with the whole system in 'cold' thermal equilibrium with the cold circulation supplying all plates. Once adequate time has elapsed for the plates and enclosed wall to reach equilibrium (usually overnight), then simultaneously the required valves were turned, redirecting the flow so that the cold circulation unit only served the cold side of the wall and now the hot circulation unit serves the hot side of the wall. Due to the very low thermal mass of the hot plate system compared with the wall section, this introduced a near step change in the temperature on this side of the wall. The test was conducted for a step change from $5^{\circ} \mathrm{C}$ to $25^{\circ} \mathrm{C}$ on the hot side while maintaining the cold side input at $5^{\circ} \mathrm{C}$ during the test. In this way the conditions for examining the thermal time constant for the wall were created. Once the recorded data showed that the plate-wall-plate system for the stepped change in temperature reached steady state $\left(\operatorname{hot} q_{x}=\operatorname{cold} q_{x}\right)$, the test was deemed complete.

\section{Results and discussion}

\subsection{Thermal time constant}

The thermal time constant is determined using the temperature difference across one of the circulation units as it reached $63.2 \%$ of its final value. Fig. 10 presents the time variations in water temperature difference $\left(T_{w o}-T_{w i}\right)$ for the hot plate expressed as a percentage of the final temperature difference after steady state has been achieved. For this wall sample the thermal time constant was achieved at $3.79 \mathrm{~h}$. 


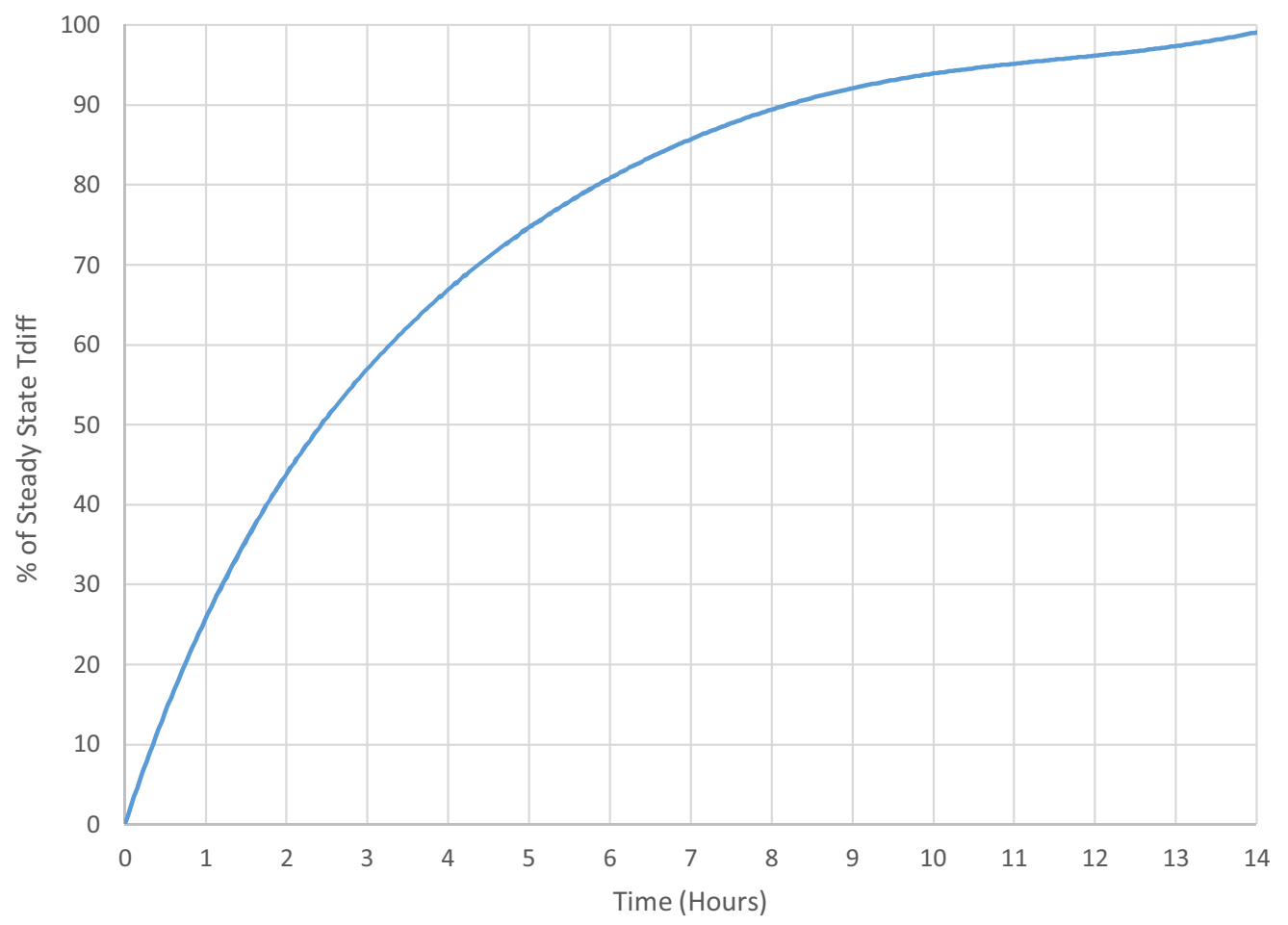

Fig. 10. Temperature difference across water channels as a percentage closeness to the final steady state condition.

The thermal time constant as defined by Givoni [50,51] can be estimated using the following equations;

$\tau=\sum_{m=1}^{n}(R C)_{m}$

$(R C)_{m}=\left[R_{1}+R_{2}+\ldots 0.5 * R_{m}\right]\left(l * \rho * c_{p}\right)_{m}$

for an element with $\mathrm{n}$ layers. More specifically, the American Testing Standard for the Hot-box Apparatus [52] recommends calculating the specimen time constants as a product $R_{\text {total }} . C$, where $R_{\text {total }}$ and C are the estimated values of the overall thermal resistance and thermal capacity of a typical wall element. When there are different routes available for heat flow through the wall, the parallel heat flow path technique is used:

$\frac{1}{\tau}=\sum_{P=1}^{n} a_{p} \frac{1}{\tau_{p}}$

$a_{p}$ is the respective fraction of a typical basic area composed of several different heat flow paths, and $\tau_{p}$ is the time constants for the path (p). However, Kossecka and Kosny [53] found that the ASTM method greatly overestimates the values for thermal time constant. Instead they found that the incorporation of the thermal structural factor $\varphi_{i e}$ allows for a more reliable estimation of multi-layered walls:

$\varphi_{\text {iep }}=\frac{1}{R_{\text {total }} 2 C_{\text {total }}} \sum_{m=1}^{n} C_{m}\left[-\frac{R_{m^{2}}}{3}+\frac{R_{m} R_{\text {total }}}{2}+R_{i-m} R_{m-e}\right]$

$\varphi_{i e}=\sum_{P=1}^{n} a_{p} \varphi_{i e p}$

$R_{m}$ and $C_{m}$ denote the thermal resistance and capacity of the m-th layer, respectively. $R_{i-m}$ and $R_{m-e}$ denote the resistance for heat transfer from surfaces of the m-th layer to the inner and outer surroundings, respectively, are calculated as follows [54];

$$
\begin{aligned}
& R_{i-m}=R_{i}+\sum_{s=1}^{m-1} R_{s i} \\
& R_{m-e}=R_{e}+\sum_{s=m+1}^{n} R_{s e}
\end{aligned}
$$

In the case of the present test facility, the surface resistances in the above equations are replaced by the resistance of the thermal mats. Contact resistance is assumed to be negligible compared to the resistance of the system and is therefore not included. Overall thermal resistance and capacity are found using the following equations;

$\frac{1}{R_{\text {total }}}=\sum_{P=1}^{n} a_{p} \frac{1}{R_{p}}$

$C_{\text {total }}=\sum_{P=1}^{n} a_{p} C_{p}$

The thermal time constant multiplies these values by the total thermal structural factor;

$\tau=R_{\text {total }} C_{\text {total }} \varphi_{\text {ie }}$

Two flow paths were identified for the wall sample, through the solid block $\left(a_{p}=0.29\right)$ or through the cavity $\left(a_{p}=0.71\right)$ of the blocks. The thermal time constant was calculated using all three methods to determine the most applicable for use with the present facility and compared to the measured thermal time constant and are tabulated in Table 4.

The Kossecka and Kosny [53] method predicted the thermal time constant to the greatest accuracy. Similar to their tests, the predicted value here was within minutes of the value obtained. 


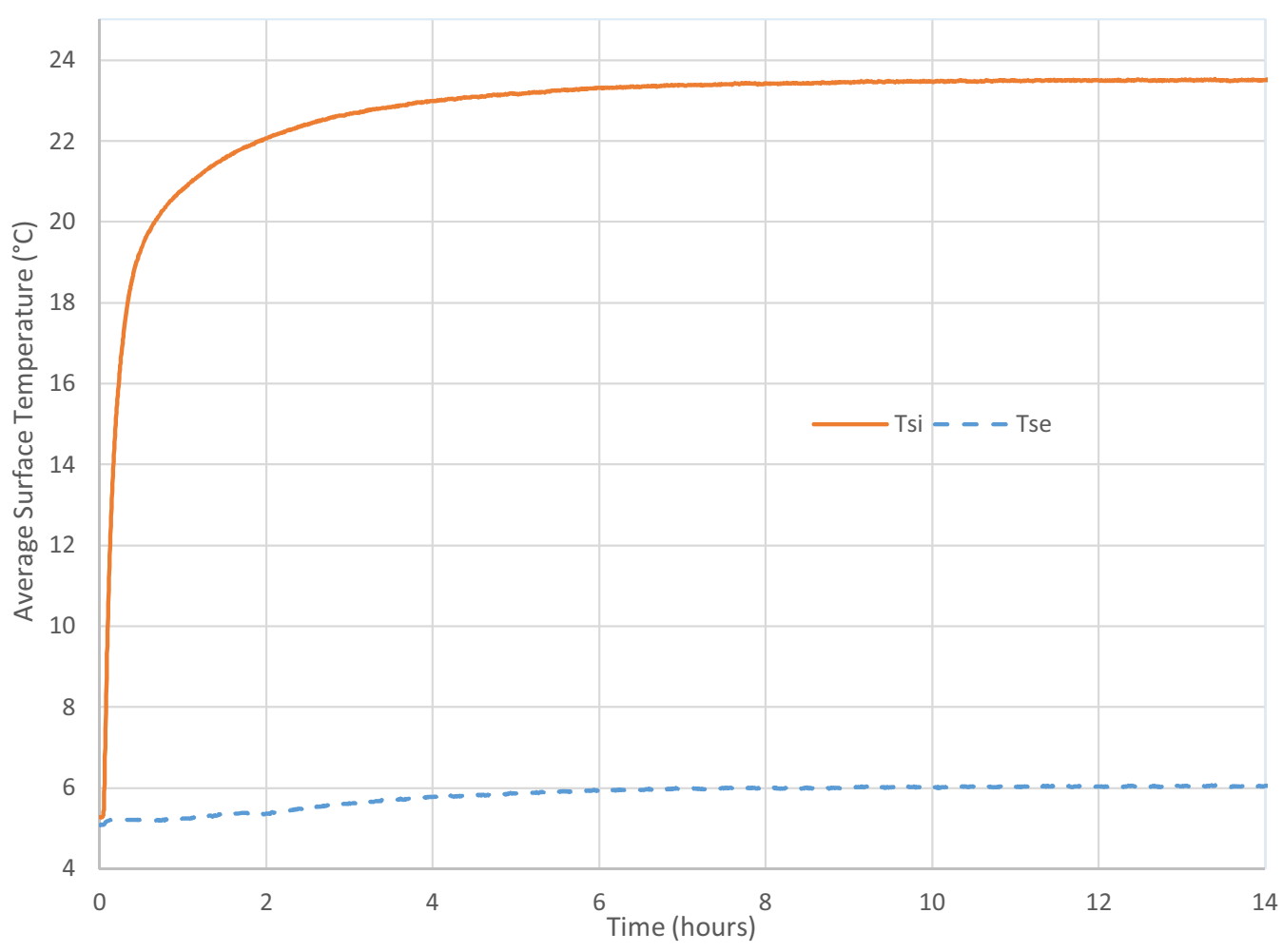

Fig. 11. Step change in circulation unit settings to $25^{\circ} \mathrm{C}$ on one side, both sides starting at $5^{\circ} \mathrm{C}$, for the cavity block wall.

Table 4

thermal time constant as estimated through calculation and measured through testing (Fig. 11)

\begin{tabular}{lll}
\hline No insulation & $\tau$ (hours) & \% steady \\
\hline ASTM [52] & 9.01 & $90.55 \%$ \\
Givoni [51] & 13.88 & $97.75 \%$ \\
Kossecka and Kosny [53] & 4.08 & $66.67 \%$ \\
Measured & 3.79 & $63.2 \%$ \\
\hline
\end{tabular}

Table 5

Repeatability of the steady state test results using different boundary conditions.

\begin{tabular}{lllll}
\hline$q_{x}(\mathrm{~W})$ & $T_{\text {ave,hot }}\left({ }^{\circ} \mathrm{C}\right)$ & $T_{\text {ave, cold }}\left({ }^{\circ} \mathrm{C}\right)$ & $R_{\text {wall }}(\mathrm{K} / \mathrm{W})$ & $R_{\text {wall }}(\mathrm{m} 2 \mathrm{~K} / \mathrm{W})$ \\
\hline 53.00 & 29.43 & 9.75 & 0.378 & 0.306 \\
62.12 & 31.07 & 7.97 & 0.373 & 0.302 \\
90.58 & 41.43 & 8.24 & 0.367 & 0.297
\end{tabular}

\subsection{Steady state}

The repeated steady-state tests found the thermal resistance of the wall sample to be $0.302 \mathrm{~m}^{2} \mathrm{~K} / \mathrm{W} \pm 1.5 \%$ after losses through the rig walls have been accounted for. The repeated test and resulting thermal resistance for the wall sample is presented in Table 5 for different boundary conditions. Within experimental uncertainty (Table 3), these three results for thermal resistance are effectively equal.

The manufacturer provided thermal resistance of the blocks $\left(0.21 \mathrm{~m}^{2} \mathrm{~K} / \mathrm{W}\right)$ and thermal mats $\left(0.002 \mathrm{~m}^{2} \mathrm{~K} / \mathrm{W}\right)$, and standard values of conductivity used to determine the resistance of the internal surface plaster $\left(0.05 \mathrm{~m}^{2} \mathrm{~K} / \mathrm{W}\right)$ and external surface render $\left(0.035 \mathrm{~m}^{2} \mathrm{~K} / \mathrm{W}\right)$ were used to calculated thermal resistance of the wall as $0.299 \mathrm{~m}^{2} \mathrm{~K} / \mathrm{W}$ [9]. Simulations using Irish hollow block only found the thermal resistance of the wall to be $0.238 \mathrm{~m}^{2} \mathrm{~K} / \mathrm{W}$ [55]. If the render and plaster is added on to this value the total increases to $0.286 \mathrm{~m}^{2} \mathrm{~K} / \mathrm{W}$. Therefore, it has been shown that the thermal resistance measured in this test is comparable to the calculated value (within 1\%) using the standard procedure and to simulations (within 5.6\%), which falls within the determined uncertainty for the procedure.

\section{Conclusion}

This paper presented the design of a facility for testing the thermal properties of wall samples. The intention of designing this facility was to determine the effective thermal resistance of wall assemblies using simple conductive heat transfer across the wall by implementing isothermal boundary conditions. Thus, the thermal resistance of the wall alone can be estimated, excluding convection and radiation heat transfer which forms part of the Hot-Box calculation. This rig offers a more straightforward and compact alternative to the traditional Hot-Box apparatus by eliminating the large convection chambers and air handling and conditioning systems, and therefore eliminating the need for determining surface resistances, which the author argues allows for a more accurate measurement of the thermal resistance of the wall itself. Under in situ conditions, heat transfer methods of radiation and convection around the internal and external surfaces are difficult to replicate precisely under laboratory conditions as they vary depending on climatic conditions, exposure levels, surface emissivities among many other site influences. However, the wall structure itself does not permanently change due to climatic conditions that are varying and temporary, which gives credence to this test methodology that does not depend on them.

This work presents the first steps towards future work which began with a determination of the thermal resistance and thermal time constant of a typically used external wall structure. The thermal resistance of the hollow block wall type was compared to tabulated and calculated values to verify the method. After careful 
design, construction, and calibration, the apparatus detailed in this study achieved agreement of calculated value within experimental uncertainty. A thermal resistance value of $0.302 \mathrm{~m}^{2} \mathrm{~K} / \mathrm{W} \pm 1.5 \%$ was determined using the rig compared to $0.299 \mathrm{~m}^{2} \mathrm{~K} / \mathrm{W}$ using the standardised methods and material property values. Furthermore, the thermal time constant measured using the rig $(3.79 \mathrm{~h})$ agreed very well with the most up to date estimation calculation method $(4.08 \mathrm{~h})$. Albeit developed for the Hot-Box technique, it is concluded that this predictive technique can, therefore, be used with this new facility and methodology with sufficient accuracy.

\section{Acknowledgements}

This research was funded through The School of Engineering scholarship award at Trinity College Dublin. We thank Cosihomes of Derchil Ltd. for donating the materials for the wall sample.

\section{References}

[1] BPIE, Europe's Buildings Under the Microscope - a country-by-country Review of the Energy Performance of Buildings, 2011.

[2] European Commission, Communication from the Commission to the European Parliament, the Council, the European Economic and Social Committee and the Committee of the Regions -A Roadmap for Moving to a Competitive Low Carbon Economy in 2050, 2011.

[3] European Parliament and Council of the European Union, Directive 2010/31/EU of the European Parliament and of the Council of 19 May 2010 on the energy performance of buildings (recast), 2010.

[4] European Commission, 'Report from the Commission to the European Parliament and the Council: Progress of Member States Towards Nearly-Zero Energy Buildings' Brussels, 2013.

[5] European Commission, Report from the Commission to the European Parliament and the Council: Progress by Member States in reaching cost-optimal levels of minimum energy performance requirements, Brussels, 2016.

[6] DOECLG, and SEAI, Report on the Development of Cost Optimal Calculations and Gap Analysis for Buildings in Ireland Under Directive 2010/31/EU on the Energy Performance of Buildings (Recast): Prepared by AECOM, 2013.

[7] DCLG, Energy Performance of Buildings Directive (recast) - Cost Optimal Calculations: UK Report to European Commission, Department for Communities and Local Government, London, 2013.

[8] F.P. Incropera, D.P. DeWitt, Fundamentals of Heat and Mass Transfer, 5th ed., Wiley, Chichester, 2001

[9] BS EN ISO 6946:2007, Building Components and Building Elements - Thermal Resistance and Thermal Transmittance - Calculation Method, British Standards Institution, 2013

[10] K.E.A. Ohlsson, R. Östin, S. Grundberg, T. Olofsson, Dynamic model for measurement of convective heat transfer coefficient at external building surfaces, J. Build. Eng. 7 (2016) 239-245.

[11] M. Mirsadeghi, D. Cóstola, B. Blocken, J.L.M. Hensen, Review of external convective heat transfer coefficient models in building energy simulation programs: implementation and uncertainty, Appl. Therm. Eng. $56(1-2)$ (2013) 134-151

[12] W.H. McAdams, Heat Transmission, McGraw-Hill Kogakusha, Tokyo, Japan, 1954.

[13] T. Stathopoulos, H. Wu, Generic models for pedestrian-level winds in built-up regions, J. Wind Eng. Ind. Aerodyn. 54-55 (C) (1995) 515-525.

[14] R. Yoshie, A. Mochida, Y. Tominaga, H. Kataoka, K. Harimoto, T. Nozu, T Shirasawa, Cooperative project for CFD prediction of pedestrian wind environment in the Architectural Institute of Japan, J. Wind Eng. Ind. Aerodyn. 95 (9-11) (2007) 1551-1578.

[15] I. Beausoleil-Morrison, An algorithm for calculating convection coefficients for internal building surfaces for the case of mixed flow in rooms, Energy Build. 33 (4) (2001) 351-361.

[16] S. Obyn, G. van Moeseke, Variability and impact of internal surfaces convective heat transfer coefficients in the thermal evaluation of office buildings, Appl. Therm. Eng. 87 (2015) 258-272.

[17] C. Marino, F. Minichiello, W. Bahnfleth, The influence of surface finishes on the energy demand of HVAC systems for existing buildings, Energy Build. 95 (2015) 70-79.

[18] J. Han, L. Lu, H. Yang, Investigation on the thermal performance of different lightweight roofing structures and its effect on space cooling load, Appl. Therm. Eng. 29 (11-12) (2009) 2491-2499.

[19] Y.A. Çengel, Steady Heat Conduction, Heat and Mass Transfer: A Practical Approach, McGraw-Hill, 2007

[20] D. Mazzeo, G. Oliveti, N. Arcuri, Influence of internal and external boundary conditions on the decrement factor and time lag heat flux of building walls in steady periodic regime, Appl. Energy 164 (2016) 509-531.
[21] B. Yesilata, P. Turgut, A simple dynamic measurement technique for comparing thermal insulation performances of anisotropic building materials, Energy Build. 39 (9) (2007) 1027-1034.

[22] N. Sombatsompop, A.K. Wood, Measurement of thermal conductivity of polymers using an improved Lee's Disc apparatus, Polym. Test. 16 (3) (1997) 203-223.

[23] A.D. Irving, S.J.M. Dudek, G. Warren, T. Dewson, Estimating the thermal transport properties of building components, Build. Environ. 30 (3) (1995) 359-365.

[24] T. Kunc, M. Lallemand, J.B. Saulnier, Some new developments on coupled radiative-conductive heat transfer in glasses-experiments and modelling, Int. J. Heat Mass Transfer 27 (12) (1984) 2307-2319.

[25] BS EN 12667:2001, Thermal performance of building materials and products - Determination of thermal resistance by means of guarded hot plate and heat flow meter methods - Products of high and medium thermal resistance: British Standard, 2001.

[26] T. Ashour, H. Wieland, H. Georg, F.-J. Bockisch, W. Wu, The influence of natural reinforcement fibres on insulation values of earth plaster for straw bale buildings, Mater. Des. 31 (10) (2010) 4676-4685.

[27] Y. Gao, J.J. Roux, C. Teodosiu, L.H. Zhao, Reduced linear state model of hollow blocks walls, validation using hot box measurements, Energy Build. 36 (11) (2004) 1107-1115.

[28] BE EN ISO 8990:1994, ISO 8990:1994(en) Thermal insulation Determination of steady-state thermal transmission properties - Calibrated and guarded hot box, 1994.

[29] BE EN 1934:1998, Thermal performance of buildings - Determination of thermal resistance by hot box method using heat flow meter: British Standard, 1998.

[30] BS EN ISO 8990:1996, Thermal insulation. Determination of steady-state thermal transmission properties. Calibrated and guarded hot box: British Standard, 1996.

[31] J.M. Sala, A. Urresti, K. Martín, I. Flores, A. Apaolaza, Static and dynamic thermal characterisation of a hollow brick wall: tests and numerical analysis, Energy Build. 40 (8) (2008) 1513-1520.

[32] K. Martín, I. Flores, C. Escudero, A. Apaolaza, J.M. Sala, Methodology for the calculation of response factors through experimental tests and validation with simulation, Energy Build. 42 (4) (2010) 461-467.

[33] T. Nussbaumer, K.G. Wakili, C. Tanner, Experimental and numerical investigation of the thermal performance of a protected vacuum-insulation system applied to a concrete wall, Appl. Energy 83 (8) (2006) $841-855$.

[34] J. Langmans, R. Klein, S. Roels, Hygrothermal risks of using exterior air barrier systems for highly insulated light weight walls: a laboratory investigation, Build. Environ. 56 (2012) 192-202.

[35] C. Buratti, E. Belloni, L. Lunghi, A. Borri, G. Castori, M. Corradi, Mechanical characterization and thermal conductivity measurements using of a new 'small hot-box' apparatus: innovative insulating reinforced coatings analysis, J. Build. Eng. 7 (2016) 63-70.

[36] A. de Gracia, C. Barreneche, M.M. Farid, L.F. Cabeza, New equipment for testing steady and transient thermal performance of multilayered building envelopes with PCM, Energy Build. 43 (12) (2011) 3704-3709.

[37] S. Ferrari, V. Zanotto, Approximating Dynamic Thermal Behaviour of the Building Envelope, Building Energy Performance Assessment in Southern Europe, Springer, 2016

[38] A. Byrne, G. Byrne, G. O'Donnell, A. Robinson, Case studies of cavity and external wall insulation retrofitted under the Irish Home Energy Saving Scheme: technical analysis and occupant perspectives, Energy Build. 130 (2016) 420-433.

[39] A. Byrne, Case Study of the Home Energy Saving Scheme: A Multidisciplinary Approach, Engineering, Trinity College Dublin, 2014.

[40] J.D. Crossen, S.E. Chidiac, R.G. Drysdale, A case for hollow clay masonry in modern construction, 10th Canadian Masonry Symposium Banff (2005).

[41] G. Huelsz, G. Barrios, J. Rojas, Equivalent-homogeneous-layers-set method for time-dependent heat transfer through hollow-block walls, Appl. Therm. Eng. 102 (2016) 1019-1023.

[42] A. Lyons, Blocks and Blockwork, Materials for Architects and Builders, Elsevier, Oxford, 2007, pp. 32-48.

[43] C. Long, Essential Heat Transfer Essex, Pearson Education Limited, 1999.

[44] ASTM STP 470, Manual on the Use of Thermocouples in Temperature Measurement, ASTM International, 1970.

[45] S.J. Kline F.A. McClintock, Describing uncertainties in single sample experiments, 1953.

[46] BS EN ISO 10456:2007, Building Materials and Products - Hygrothermal Properties - Tabulated Design Values and Procedures for Determining Declared and Design Thermal Values (incorporating Corrigendum December 2009), British Standards Institution, 2007.

[47] Department of the Environment Heritage and local Government, Building Regulations 2007, Technical Guidance Document L: Conservation of Fuel and Energy - Dwellings, The Stationary Office, 2007.

[48] CIBSE, Guide A: Environmental Design, CIBSE Publications, London, 2007.

[49] Roadstone Ltd., Sandard Blocks: Product Summary, 1997.

[50] B. Givoni, Climate Man and Architecture, 2nd ed., Applied Science Publishers, London, 1976.

[51] B. Givoni, Climate Considerations in Buildings and Urban Design, 2nd ed., International Thomson Reinhold, 1998. 
[52] ASTM C1363-97, Standard Test Method for the Thermal Performance of Building Assemblies by Means of a Hot Box Apparatus, ASTM, International, West Conshohocken, PA, 1997.

[53] E. Kossecka, J. Kosny, Hot-Box testing of building envelope assemblies - a simplified procedure for estimation of minimum time of the test, J. Test. Eval. 36 (3) (2008) 242-249.
[54] E. Kossecka, The effect of structure on dynamic thermal characteristics of multi-layer walls, Arch. Civil Eng. 42 (3) (1996) 351-369.

[55] J. Little, B. Arregi, An Independent Analysis of the Thermal Characteristics of Irish Concrete Hollow Blocks and Hollow Block Wall Upgrades and a Discussion in Hollow Block Design, Joseph Little Architects, 2009. 